\title{
Expression profiles of urbilaterian genes uniquely shared between honey bee and vertebrates
}

\author{
Toshiaki Matsui ${ }^{1}$, Toshiyuki Yamamoto ${ }^{1}$, Stefan Wyder $^{2}$, \\ Evgeny M Zdobnov²,3,4 and Tatsuhiko Kadowaki*5
}

\author{
Address: ${ }^{1}$ Department of Applied Biological Sciences, School of Agricultural Sciences, Nagoya University, Chikusa, Nagoya 464-8601, Japan, \\ 2Department of Genetic Medicine and Development, University of Geneva Medical School, 1 rue Michel-Servet, 1211 Geneva, Switzerland, ${ }^{3}$ Swiss \\ Institute of Bioinformatics, 1 rue Michel-Servet, 1211 Geneva, Switzerland, ${ }^{4}$ Imperial College London, South Kensington Campus, SW7 2AZ, \\ London, UK and ${ }^{5}$ Graduate School of Bioagricultural Sciences, Nagoya University, Chikusa, Nagoya 464-8601, Japan \\ Email: Toshiaki Matsui - matsu_toshi_@msn.com; Toshiyuki Yamamoto - bibibibi-binchan@docomo.ne.jp; \\ Stefan Wyder - Stefan.Wyder@medecine.unige.ch; Evgeny M Zdobnov - zdobnov@medecine.unige.ch; \\ Tatsuhiko Kadowaki* - emi@nuagr1.agr.nagoya-u.ac.jp \\ * Corresponding author
}

Published: 12 January 2009

BMC Genomics 2009, 10:17 doi:10.1186/147|-2164-10-17
Received: 8 August 2008

Accepted: 12 January 2009

This article is available from: http://www.biomedcentral.com/I47I-2/64/10/17

(C) 2009 Matsui et al; licensee BioMed Central Ltd.

This is an Open Access article distributed under the terms of the Creative Commons Attribution License (http://creativecommons.org/licenses/by/2.0), which permits unrestricted use, distribution, and reproduction in any medium, provided the original work is properly cited.

\begin{abstract}
Background: Large-scale comparison of metazoan genomes has revealed that a significant fraction of genes of the last common ancestor of Bilateria (Urbilateria) is lost in each animal lineage. This event could be one of the underlying mechanisms involved in generating metazoan diversity. However, the present functions of these ancient genes have not been addressed extensively. To understand the functions and evolutionary mechanisms of such ancient Urbilaterian genes, we carried out comprehensive expression profile analysis of genes shared between vertebrates and honey bees but not with the other sequenced ecdysozoan genomes (honey bee-vertebrate specific, HVS genes) as a model.

Results: We identified 30 honey bee and 55 mouse HVS genes. Many HVS genes exhibited tissueselective expression patterns; intriguingly, the expression of $60 \%$ of honey bee HVS genes was found to be brain enriched, and $24 \%$ of mouse HVS genes were highly expressed in either or both the brain and testis. Moreover, a minimum of $38 \%$ of mouse HVS genes demonstrated neuronenriched expression patterns, and $62 \%$ of them exhibited expression in selective brain areas, particularly the forebrain and cerebellum. Furthermore, gene ontology (GO) analysis of HVS genes predicted that $35 \%$ of genes are associated with DNA transcription and RNA processing.

Conclusion: These results suggest that HVS genes include genes that are biased towards expression in the brain and gonads. They also demonstrate that at least some of Urbilaterian genes retained in the specific animal lineage may be selectively maintained to support the species-specific phenotypes.
\end{abstract}

\section{Background}

Cross-species comparison of genome sequences and expressed sequence tag (EST) data sets have given us enormous insight into the evolution of metazoan genomes. In particular, the recent completion of a number of ecdysozoan and deuterostome genome projects as well as the collection of massive EST data on lophotrochozoan and cnidarians enable us to identify orthologous groups of 
genes and gene losses in these 4 major metazoan clades. Research on Acropora millepora (anthozoa, cnidaria) supports the view that a significant proportion of genes present only in the vertebrates and absent in model invertebrates is not a vertebrate-specific evolutionary change. Instead, these genes appear to have been lost in the specific metazoan lineages that branched from common ancestors during evolution [1]. The same conclusion is reached by considering the fact that sea anemone Nematostella vectensis contains many Wnt subfamilies that were lost from Drosophila and Caenorhabditis [2-4]. The crossspecies comparison of Aplysia californica EST data sets with other metazoan genomes and with Platynereis dumerilii demonstrate that gene loss and sequence divergence are most extensive in model ecdysozoans (fruit fly and nematode), and lophotrochozoans are less derived from the complex ancestral genome of Urbilateria [5,6]. Urbilateria is a common ancestor of Bilateria, and 3 major clades (ecdysozoa, lophotrochozoa, and deuterostome) subsequently branched off from it [7].

Honey bees belong to the Hymenoptera, one of the 4 large holometabolous insect orders. They are highly social insects and have been used as a model system to study complex animal behavior and cognitive ability comparable to those of some vertebrates [8-10]. Furthermore, caste differentiation (differentiation of fertile queen and sterile worker, polyphenism) and sex determination via haplodiploidy (haploids and diploids develop into males and females, respectively) are specific to some hymenopterans such as honey bees, among the holometabolous insects. The completion of genome sequencing of several species in the 4 major holometabolous insect orders (Diptera, Lepidoptera, Hymenoptera, and Coleoptera), namely fruit flies (12 Drosophila species) [11], mosquitoes (Anopheles gambiae [12] and Aedes aegypti [13]), silk moth (Bombyx mori) [14], and honey bee (Apis mellifera) [15] and red flour beetle (Tribolium castaneum) [16] promises to provide new insights into how the genomes of holometabolous insects evolved in comparison to those of other metazoans. A comparison of the above insect genomes has revealed that a number of genes are lost in specific insects, but they are present in the other insects and vertebrates. These are the ancient genes of Urbilateria, which were retained in some species but lost from others. The loss and retention of these ancient genes in specific lineages are implicated in generating metazoan diversity; however, the causal relationships acting therein have not been studied extensively. We, therefore, identified genes shared between vertebrates and honey bees but absent in the other sequenced insect and nematode genomes, and we characterized their expression profiles in various honey bee and mouse tissues as well as the mouse brain to gain insight into their present functions in honey bees and mice. Furthermore, we expected that this study would give us clues to ascertain whether these genes have been selectively or randomly retained in the specific species during evolution. Our results demonstrate that the ancient Urbilaterian genes uniquely shared between honey bee and vertebrates are biased towards expression and functioning in the brain (often in specific regions) and testis. Their possible functions and evolutionary mechanisms will be discussed further.

\section{Results \\ Identification of genes specifically conserved between vertebrates and honey bee but lost from the other sequenced ecdysozoan genomes}

We identified candidate genes shared between at least 1 vertebrate (among Homo sapiens, Mus musculus, Monodelphis domestica, Gallus gallus, and Tetraodon nigroviridis) and the honey bee but not with 3 dipterans (D. melanogaster, A. gambiae, and A. aegypti) and a coleopteran (T. castaneum) species by automatic large-scale sequence analysis, as described in Methods [17]. We, then, performed a TBLASTN analysis of these candidate genes with the genomic and gene model sequences of the above insects as well as those of B. mori (Lepidoptera) and C. elegans. We discarded the ones that showed significant similarity with an E value < 1E-03. This screening resulted in the identification of 30 honey bee genes shared with vertebrates, but not with other sequenced insect and nematode genomes. We named them HVS (honey bee-vertebrate specific) genes, and they are listed together with the mouse homologs in Table 1. Twenty-one honey bee HVS genes encode proteins with known domains and/or functions. These include, for example, DNA methyltransferase Dnmt3 (GB14232), which has been reported previously [18]; homeodomain only protein (GB16549), which is highly expressed in the mouse brain [19] and heart $[20,21]$; Tuba (GB13871), which is a Cdc42-specific guanine nucleotide exchange factor to regulate actin polymerization [22]; and prenylcysteine oxidase 1 (prenylcysteine lyase, GB15533), a lysosomal enzyme degrading prenylcysteine [23].

\section{Distribution patterns of HVS genes in sequenced deuterostome genomes}

We analyzed the copy numbers of HVS genes among the sequenced deuterostome (Strongylocentrotus purpuratus, Ciona intestinalis, T. nigroviridis, Xenopus tropicalis, G. gallus, M. musculus, and $H$. sapiens) genomes, and the results are shown in Table 2. Deuterostomes appear to retain most of the HVS genes, in contrast to ecdysozoans. Although each HVS gene is present as a single copy in the honey bee genome, multiple-copy HVS genes are often present in the deuterostome genomes. All of the HVS genes, except Dnmt3; tumor necrosis factor (TNF) receptor superfamily; Tmem45; and F-box and leucine-rich repeat protein genes, are present as single copies in both sea urchin and 
Table I: List of honey bee and mouse HVS genes

\begin{tabular}{|c|c|c|c|c|c|c|}
\hline \multirow{2}{*}{$\begin{array}{l}\text { Apis } \\
\text { GLEAN model } \\
\text { Proteins with } \mathrm{kr}\end{array}$} & \multirow{2}{*}{$\begin{array}{l}\text { Mouse Accession Number } \\
\text { hown domains }\end{array}$} & \multirow{2}{*}{ E-value } & \multicolumn{2}{|l|}{ Name/Comments } & \multicolumn{2}{|c|}{ Tissues highly expressed } \\
\hline & & & & & Honey bee & Mouse \\
\hline GBI3403 & NP_084053.2 & $2.00 \mathrm{E}-34$ & Rhbdd I & rhomboid domain containing I & Ubiquitous & Ubiquitous \\
\hline GBI5999 & NP_001001 I84.I & $2.00 \mathrm{E}-60$ & CcdclII & $\begin{array}{l}\text { coiled-coil domain containing } \\
\text { III }\end{array}$ & Brain & Selective \\
\hline \multirow[t]{2}{*}{ GBI6203 } & NP_083670.I & $2.00 \mathrm{E}-12$ & $\operatorname{Sn} \times 24$ & sorting nexing 24 & Brain/Abdomen & Spleen \\
\hline & NP_001020783.I & $6.00 \mathrm{E}-12$ & Sn $\times 22$ & sorting nexing 22 & & Selective \\
\hline \multirow[t]{2}{*}{ GBI7738 } & NP_598396.I & $2.00 \mathrm{E}-53$ & Rtkn & rhotekin & Brain/Thorax & Selective \\
\hline & XP_925652.I & $3.00 \mathrm{E}-50$ & LOC631847 & $\begin{array}{l}\text { similar to pleckstrin homology } \\
\text { domain containing, family K } \\
\text { member I }\end{array}$ & & Lung \\
\hline \multirow[t]{2}{*}{ GBI387I } & NP_082305.I & $8.00 \mathrm{E}-53$ & Tuba & dynamin binding protein & Brain & Selective \\
\hline & NP_808496.I & $6.00 \mathrm{E}-47$ & 4933429F08Rik & $\begin{array}{l}\text { hypothetical protein } \\
\text { LOC } 328967\end{array}$ & & Brain/Testis \\
\hline \multirow[t]{2}{*}{ GB I 4232} & NP_001003963.I & 4.00E-82 & Dnmt3b & DNA methyltransferase 3B & Brain/Abdomen & Brain/Testis \\
\hline & NP_03 I 898.I & 8.00E-74 & Dnmt3a & DNA methyltransferase 3A & & Ubiquitous \\
\hline \multirow[t]{2}{*}{ GBI5274 } & NP_033873.3 & I.00E-09 & $\mathrm{Bcl} 2 \mathrm{II}$ & Bcl2-like I & Brain/Abdomen & Selective \\
\hline & NP_803129 & I.00E-07 & $\mathrm{Bc} 12$ & B-cell leukemia/lymphoma 2 & & Selective \\
\hline \multirow[t]{2}{*}{ GBI5533 } & NP_080099.I & $3.00 \mathrm{E}-16$ & Pcyoxl & prenylcysteine oxidase I & Brain & Brain \\
\hline & NP_766420.I & $6.00 \mathrm{E}-16$ & PcyoxII & prenylcysteine oxidase I like & & Selective \\
\hline GB I 6549 & NP_783 I99.I & $9.00 \mathrm{E}-08$ & Hop & homeodomain only protein & Ubiquitous & Selective \\
\hline GBI6908 & NP_067303.I & $4.00 \mathrm{E}-20$ & Bin3 & bridging integrator 3 & Brain & Selective \\
\hline \multirow[t]{2}{*}{ GBI 7445} & NP_035789.I & $5.00 \mathrm{E}-07$ & Tnfrsf4 & $\begin{array}{l}\text { tumor necrosis factor receptor } \\
\text { superfamily, member } 4\end{array}$ & Brain/Abdomen & Selective \\
\hline & NP_849262.I & I.00E-06 & Tnfrsfl 4 & $\begin{array}{l}\text { tumor necrosis factor receptor } \\
\text { superfamily member } 14\end{array}$ & & Selective \\
\hline GBI47I7 & NP_00I 028486.1 & I.00E-37 & C530028I08Rik & $\begin{array}{l}\text { hypothetical protein } \\
\text { LOC232933 }\end{array}$ & Brain & Testis \\
\hline \multirow[t]{2}{*}{ GB I 5370} & NP_080I 42.1 & $4.00 E-4 I$ & Cdca7 & $\begin{array}{l}\text { cell division cycle associated } \\
7\end{array}$ & Brain/Thorax & Brain/Testis \\
\hline & NP_666I52.I & $2,00 E-40$ & Cdca7l & $\begin{array}{l}\text { cell division cycle associated } \\
7 \text { like }\end{array}$ & & Selective \\
\hline GB I 4468 & NP_067360.I & 3.00E-50 & Rad I 8 & RAD I 8 homolog & Brain & Testis \\
\hline \multirow[t]{2}{*}{ GBI0755 } & NP_659185.I & $4.00 \mathrm{E}-10$ & Tmem45b & transmembrane protein $45 \mathrm{~b}$ & Brain & Selective \\
\hline & NP_062605.2 & $6.00 \mathrm{E}-03$ & Tmem45a & transmembrane protein $45 a$ & & Selective \\
\hline \multirow[t]{2}{*}{ GBI876I } & NP_038957.I & $2.00 \mathrm{E}-13$ & Sival & $\begin{array}{l}\text { Cd27 binding protein } \\
\text { (Hindu God of destruction) }\end{array}$ & Brain & Ubiquitous \\
\hline & $X P_{-} 486223$ & $6.00 \mathrm{E}-07$ & LOC434405 & $\begin{array}{l}\text { similar to Apoptosis regulatory } \\
\text { protein Siva }\end{array}$ & & Ubiquitous \\
\hline GBI0273 & NP_082325.I & I.00E-II & Fbxo22 & F-box protein 22 & Brain & Ubiquitous \\
\hline \multirow[t]{2}{*}{ GBI 8346} & $X P_{-} / 38107$ & $9.00 \mathrm{E}-47$ & LOC217738 & $\begin{array}{l}\text { similar to thrombospondin, type } \\
\text { I domain containing } 3\end{array}$ & Brain & Brain/Testis \\
\hline & XP_996152 & I.00E-45 & 5430433G2 IRik & similar to isthmin I & & Lung \\
\hline GBI 8120 & NP_084460.I & $5.00 \mathrm{E}-23$ & Armc9 & armadillo repeat containing 9 & Brain & Brain/Testis \\
\hline GBI 8050 & NP_0831 I6.I & 4.00E-09 & Armcl & $\begin{array}{l}\text { armadillo repeat-containing } \\
\text { protein }\end{array}$ & Brain & Ubiquitous \\
\hline \multirow[t]{2}{*}{ GBI9733 } & NP_056637.I & I.00E-50 & $\mathrm{Fbxl3}$ & $\begin{array}{l}\text { F-box and leucine-rich repeat } \\
\text { protein } 3\end{array}$ & Brain & Ubiquitous \\
\hline & NP_848789.2 & $1.00 \mathrm{E}-46$ & $\mathrm{Fbx|2I}$ & $\begin{array}{l}\text { F-box and leucine-rich repeat } \\
\text { protein } 21\end{array}$ & & Selective \\
\hline
\end{tabular}

Proteins without known domains

\begin{tabular}{|c|c|c|c|c|c|c|}
\hline \multirow[t]{2}{*}{ GBI8937 } & NP_080777.I & $3.00 \mathrm{E}-06$ & | 3000I0M03Rik & hypothetical protein LOC67998 & Ubiquitous & Ubiquitous \\
\hline & NP_001030023.I & 8.00E-04 & 18100|5C04Rik & hypothetical protein LOC 66270 & & Selective \\
\hline GBI9|46 & NP_950182.1 & $2.00 \mathrm{E}-15$ & 92301 I0CI9Rik & $\begin{array}{l}\text { hypothetical protein } \\
\text { LOC234912 }\end{array}$ & Brain & Selective \\
\hline GBIIOIO & NP_780695.I & I.00E-08 & 643057ILI3Rik & $\begin{array}{l}\text { hypothetical protein } \\
\text { LOC235599 }\end{array}$ & Brain & Selective \\
\hline GBI 7260 & XP_989436.I & I.00E-04 & I7000I2P22Rik & hypothetical protein LOC69364 & Brain & Brain/Testis \\
\hline
\end{tabular}


Table I: List of honey bee and mouse HVS genes (Continued)

\begin{tabular}{|c|c|c|c|c|c|c|}
\hline GBI6350 & NP_08|465.I & 2.00E-II & Gemin7 & $\begin{array}{l}\text { gem (nuclear organelle) } \\
\text { associated protein } 7\end{array}$ & Ubiquitous & Ubiquitous \\
\hline GBI427I & NP_08I498.I & I.00E-07 & 201000IM09Rik & hypothetical protein LOC698I6 & Brain & Selective \\
\hline \multirow[t]{2}{*}{ GBI7835 } & NP_082206.I & $1.00 \mathrm{E}-13$ & $2610016 C 23$ Rik & DUF729 domain containing I & Brain & Brain/Testis \\
\hline & NP_080458.I & 3.00E-09 & Mtfrl & $\begin{array}{l}\text { chondrocyte protein with a poly- } \\
\text { proline region }\end{array}$ & & Ubiquitous \\
\hline \multirow[t]{2}{*}{ GB I 8344} & NP_001028397.2 & 2.00E-08 & Pnrcl & $\begin{array}{l}\text { proline-rich nuclear } \\
\text { receptor coactivator I }\end{array}$ & Ubiquitous & Brain \\
\hline & NP_080659.I & 4.00E-07 & Pnrc2 & $\begin{array}{l}\text { proline-rich nuclear } \\
\text { receptor coactivator } 2\end{array}$ & & Ubiquitous \\
\hline GB I5864 & NP_899139.2 & 2.00E-05 & Snapc5 & $\begin{array}{l}\text { small nuclear RNA } \\
\text { activating complex, } \\
\text { polypeptide } 5\end{array}$ & Brain/Thorax & Selective \\
\hline
\end{tabular}

The genes categorized as transcription and modification of DNA as well as RNA processing by GO system are indicated with bold letters. The expression domains of honey bee and mouse HVS genes are listed in the right column. The genes ubiquitously and selectively expressed in the tissues are indicated as Ubiquitous and Selective, respectively. The genes highly expressed in the brains of both honey bee and mouse are shown with bold letters. The sequences of honey bee GLEAN models are available in BCM database http://www.hgsc.bcm.tmc.edu/projects/honeybee/ and BeeBase http://www.beebase.org/.

Table 2: Copy number of HVS genes in the deuterostome genomes

\begin{tabular}{|c|c|c|c|c|c|c|c|}
\hline A. mellifera & S. purpuratus & C. intestinalis & T. nigroviridis & X. tropicalis & G. gallus & M. musculus & H. sapience \\
\hline \multicolumn{8}{|c|}{ Genes encoding proteins with known domains } \\
\hline GBI3403 & I & 1 & I & 1 & 1 & 1 & 1 \\
\hline GBI5999 & 1 & 1 & 1 & 1 & 1 & 1 & 1 \\
\hline GBI 6203 & I & 0 & 2 & 2 & 2 & 2 & 2 \\
\hline GBI7738 & I & 1 & 2 & 2 & 1 & 2 & 2 \\
\hline GBI387। & I & 1 & 2 & 2 & 2 & 2 & 2 \\
\hline GBI4232 & 1 & 2 & 3 & 2 & 2 & 2 & 2 \\
\hline GBI5274 & I & 1 & 4 & 4 & 5 & 5 & 5 \\
\hline GBI5533 & I & 1 & 2 & 2 & 2 & 2 & 2 \\
\hline GBI 6549 & I & 1 & I & 1 & 1 & 1 & 1 \\
\hline GBI 6908 & I & 1 & 1 & 1 & 1 & 1 & 1 \\
\hline GBI 7445 & 3 & 1 & 5 & 4 & 5 & 8 & 9 \\
\hline GBI47I7 & I & I & 1 & 1 & 1 & 1 & 1 \\
\hline GBI5370 & I & I & 3 & 3 & 3 & 2 & 2 \\
\hline GBI 4468 & I & 1 & 1 & 1 & 1 & 1 & 1 \\
\hline GBI 0755 & 2 & I & 2 & 2 & 2 & 2 & 2 \\
\hline GBI876I & I & 1 & I & 1 & 1 & 2 & 2 \\
\hline GBI0273 & I & 0 & 1 & 1 & 1 & 1 & 1 \\
\hline GBI 8346 & 1 & 1 & 2 & 2 & 2 & 2 & 2 \\
\hline GBI 8120 & I & 1 & I & 1 & I & 1 & 1 \\
\hline GBI 8050 & 1 & 1 & 3 & 1 & 1 & 1 & 1 \\
\hline GB19733 & 2 & 2 & 3 & 2 & 2 & 2 & 2 \\
\hline
\end{tabular}

Genes encoding proteins without known domains

\begin{tabular}{|c|c|c|c|c|c|c|c|}
\hline GBI 8937 & 1 & I & 3 & 3 & 2 & 3 & 3 \\
\hline GBI9146 & I & I & I & I & 1 & 1 & I \\
\hline GBIIOIO & 0 & 0 & 1 & 0 & 1 & 1 & I \\
\hline GBI 7260 & 1 & I & 0 & 1 & 1 & I & I \\
\hline GBI 6350 & 1 & 0 & I & I & 0 & I & I \\
\hline GBI427I & 0 & I & 0 & 0 & 0 & I & I \\
\hline GBI 7835 & I & I & 2 & 2 & 2 & 2 & 2 \\
\hline GBI8344 & 0 & I & 2 & I & 2 & 2 & 2 \\
\hline GBI5864 & 0 & 0 & 0 & I & I & I & I \\
\hline
\end{tabular}


ascidian genomes. Thus, the duplication of HVS genes is quite specific to vertebrate lineages. The vertebrates have $4-5$ copies of $\mathrm{Bcl} 2$, one of the key regulators of apoptosis [24], and 4-9 copies of TNF receptor superfamily genes.

\section{Analysis of HVS genes by GO terms}

We predicted HVS gene functions by assigning Gene Ontology (GO) terms (Gene-Ontology database, http:// www.geneontology.org) and found that 7 out of 20 gene products were proposed to be involved in transcription and modification of DNA as well as RNA processing in the nucleus. These include Dnmt3a/3b (involved in epigenetic control, [25]), Hop (transcriptional repressor, $[20,21]$ ), Rad18 (involved in DNA repair, [26]), Cdca7/ Cdca7like, Pnrc1/2, Snapc5, and Gemin7. Gemin7 appears to be involved in RNA processing. The others are associated with the intracellular signaling cascade (for example, Rhotekin), regulation of apoptosis (Bcl2), actin filament organization (Bin3), receptor activity (TNF receptor super family), and ubiquitin cycle (Fbxo22). In Drosophila, proteins associated with the regulation of gene expression represent only $10 \%$ of the total proteins [27]. Considering that the total number of honey bee HVS genes is 30, it appears that HVS genes are biased to contain genes associated with these categories of cellular functions (Student $t$-test, $p<0.05$ ).

\section{Expression profiles of HVS genes in honey bee and mouse tissues}

To confirm mRNA expression and to determine the functional implications of HVS genes, we carried out semiquantitative RT-PCR analysis for each HVS gene with various honey bee and mouse tissues. All HVS mRNAs were expressed at various levels in the honey bee brain, thorax, and abdomen (Fig 1, Additional files 1 and 2). Ubiquitous expression was observed in the cases of GB16549, GB13403, GB18344, GB18937, and GB16350 (Fig. 1 and Additional file 2). Expressions of GB16203, GB14232, GB15274, and GB17445 mRNA were at least 2.5 times higher in the brain and abdomen than that in the thorax (Fig. 1). GB15864 and GB17738 mRNAs expression was 3 times higher in the brain and thorax than that in the abdomen, and the expression of GB15370 mRNA was weak in the abdomen (1.5 times less than that in the thorax) (Fig. 1). The remaining $60 \%$ of the honey bee HVS genes (18 out of 30) were expressed at a higher level in the brain than in the abdomen and thorax. In particular, the expressions of GB14717, GB16908, and GB10273 were exclusively detected in the brain (Additional file 2). GB13871, GB19146, GB15533, GB19733, and GB18346 mRNA expressions were $3.5,5,3,2$, and 3 times higher in the brain than in the abdomen, respectively (Fig. 1 and Additional file 2). Expressions of GB11010, GB14271, GB18120, GB14468, GB18761，GB15999, GB17835, GB17260, GB18050, and GB10755 mRNA were 3.5, 4, 4.5,

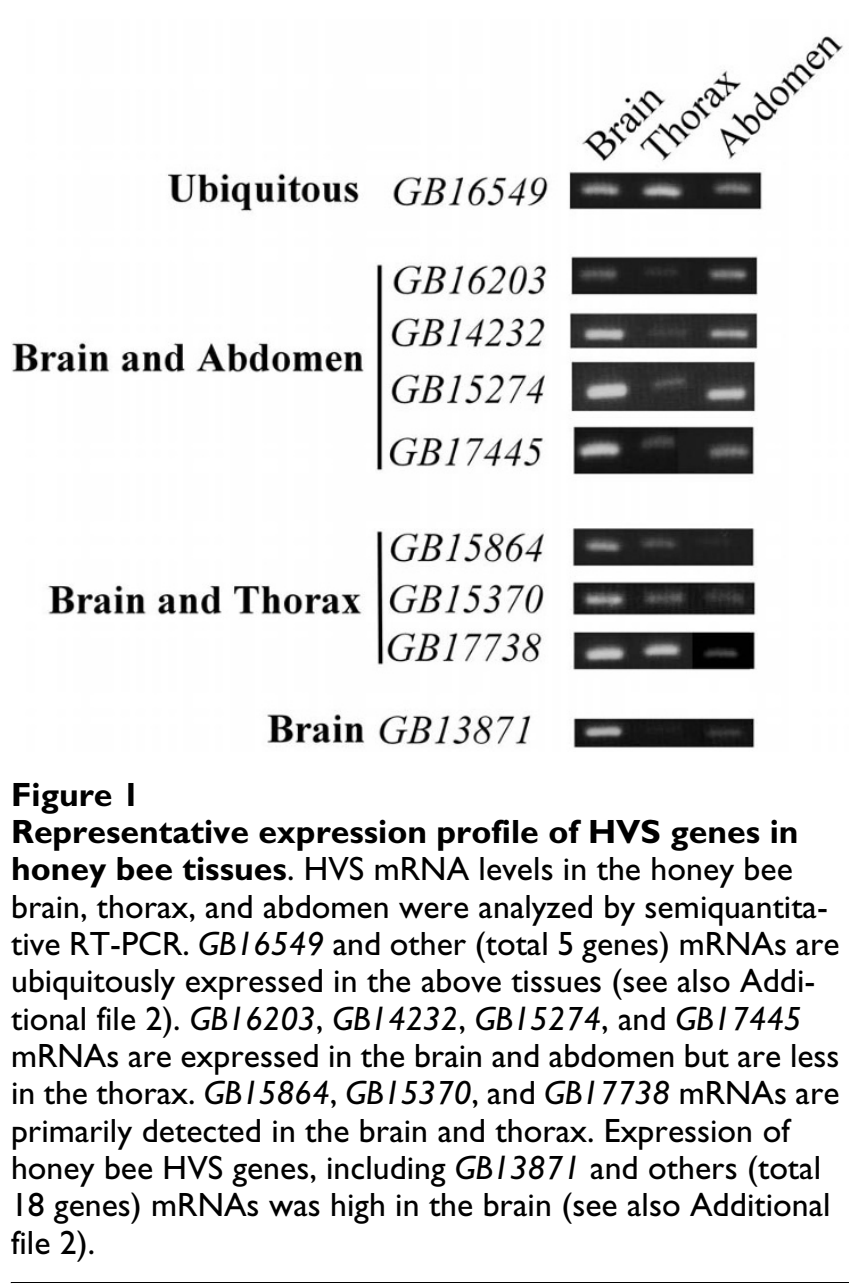

$2.5,7,2,1.5,2,1.5$, and 2 times higher in the brain than in the thorax, respectively (Additional file 2).

The expression of mouse HVS genes in various tissues was also analyzed. For mouse HVS genes with more than 3 copies in the genome, the expression of 2 genes sharing the highest similarity with the honey bee gene was analyzed. Thus, we performed semiquantitative RT-PCR analysis with 45 mouse HVS genes (see Table 1). Most of the HVS genes showed tissue-selective expression patterns in mouse (Fig. 2, Additional file 3, and Additional file 4). Ubiquitous expression was observed with Rhbdd1, Dnmt3a, Mtfr1, Armc1, Pnrc2, 1300010M03Rik, Fbxlike3, Gemin7, Siva1, LOC434405, and Fbxo22 (11 out of 45) (Fig. 2 and Additional file 3). The expressions of Pcyoxl and Pnrc1 were primarily detected in the brain (Fig. 2 and Additional file 3). C530028I08Rik and Rad18 were primarily expressed in the testis (Fig. 2 and Additional file 3). The expression levels of 4933429F08Rik, Dnmt3b, Cdca7, LOC217738, 1700012P22Rik, 2610016C23Rik, and Armc9 mRNAs were high in both the brain and testis (Fig. 2 and Additional file 3). Thus, 


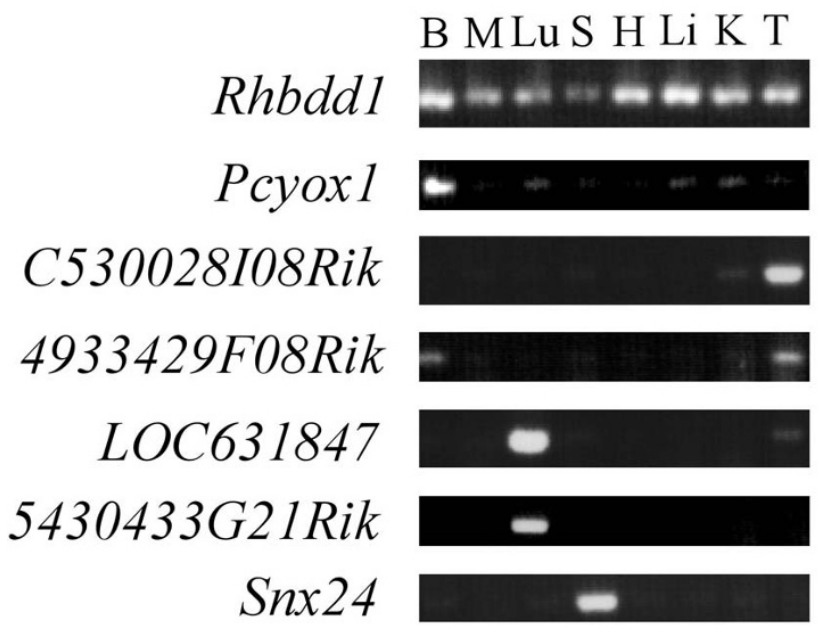

Figure 2

Representative expression profiles of HVS genes in mouse tissues. HVS mRNA expression levels in the mouse brain $(B)$, muscle $(M)$, lung $(L u)$, spleen $(S)$, heart $(H)$, liver $(\mathrm{Li})$, kidney $(\mathrm{K})$, and testis $(\mathrm{T})$ were analyzed by semiquantitative RT-PCR. Rhbdd I and other (total II genes) mRNAs are ubiquitously present in the above tissues. Expressions of Pcyoxl and Pnrcl (Additional file 3) mRNAs and those of C530028108Rik and Rad 8 (Additional file 3) were abundant in the brain and testis, respectively. 4933429F08Rik and other (total 7 genes) mRNAs were predominantly expressed in the brain and testis. See also Additional file 3. LOC63/847 and 5430433G2 I Rik mRNAs were primarily detected in the lung. Snx24 mRNA is expressed in the spleen. The remaining 20 mouse HVS genes show various "tissue-selective" expression patterns, as shown in Additional file 4.

mouse HVS genes expressed in either or both the brain and testis accounted for a total of 11 (out of 45) genes. LOC631847 and 5430433G21Rik mRNAs were highly expressed in the lung (Fig. 2). The expression of Snx24 was primarily detected in the spleen (Fig. 2). Cdca7like and 2010001M09Rik mRNAs were expressed in the brain, lung, spleen, kidney, and testis but to a lesser extent in the muscle, heart, and liver (Additional file 4). Snapc5 and Bcl2like1 were expressed in all tissues examined, except in the muscle (Additional file 4). All other genes (16 out of 45) showed different tissue-selective expression patterns (Additional file 4).

\section{Expression profiles of HVS genes in mouse brain}

Next, we characterized the spatial expression patterns of HVS genes in the mouse brain by searching data in the Allen Brain Atlas [28]. The atlas provides 2- and 3-dimensional images of the spatial expression patterns of $\sim 20,000$ genes in the adult mouse brain. In situ hybridization data are available for 34 mouse HVS genes. Among them, 20 genes exhibited only weak expression and, therefore, their expression could not be attributed to the spe- cific cell types or brain regions. Neuron-enriched expression was detected for Tuba, 4933429F08Rik, Bcl2like1, Pcyox1, Pcyox1like, Hop, Armc1, Armc9, Pnrc1, 1300010M03Rik, 1810015C04Rik, Snapc5, and Rad18 (Fig. 3 and Additional file 5). Only Fbxo22 was expression in both neurons and glial cells (Additional file 5A).
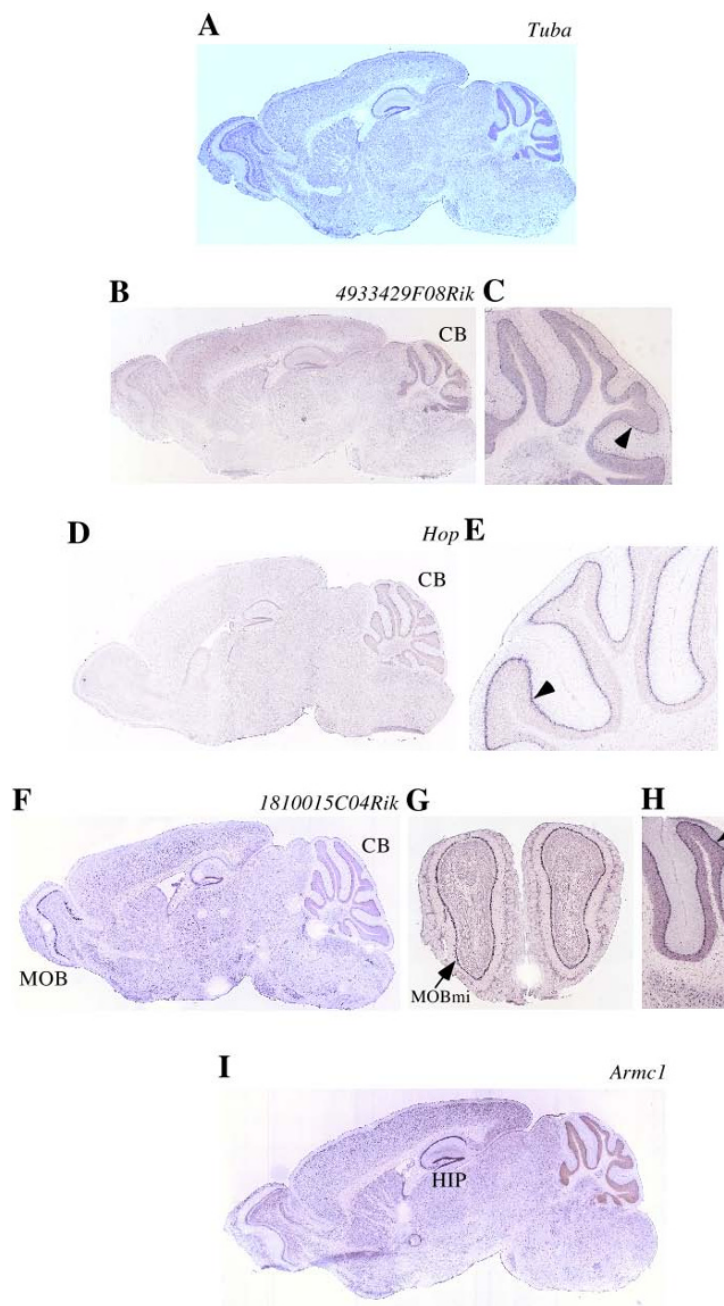

Figure 3

Spatial expression patterns of Tuba, 4933429F08Rik, Hop, I8I00I5C04Rik, and Armcl mRNAs in the adult mouse brain. Tuba mRNA is relatively well expressed in the anterior part of the brain (A). Weak expression of 4933429F08Rik mRNA is observed in the cerebellum (CB) (B), particularly in Purkinje cells (arrow head) (C). Hop mRNA is primarily detected in Purkinje cells (arrow head in E) of the cerebellum (CB) (D). Expression of 1810015C04Rik mRNA is primarily detected in the olfactory bulb (MOB) and cerebellum (CB) $(F)$. It is abundant in the mitral layer of the olfactory bulb (MOBmi in $\mathrm{G}$ ) and in cerebellar Purkinje cells (arrow head in $\mathrm{H}$ ). Armcl mRNA is expressed throughout the brain; however, it is relatively well expressed in the hippocampus (HIP) (I). 
Tuba mRNA was expressed relatively well in the anterior part of the brain (Fig. 3A); its duplicated gene 4933429F08Rik was, however, expressed in the cerebellum, particularly in Purkinje cells (Fig. 3B and 3C). The expression of Hop was primarily detected in cerebellar Purkinje cells (Fig. 3D and 3E). Expression of 1810015C04Rik mRNA was abundant in the mitral layer of the olfactory bulb and in cerebellar Purkinje cells (Fig. 3F H). The expression of Armc1 was ubiquitous throughout the entire brain; however, it was relatively well expressed in the hippocampus (Fig. 3I). Pcyox1, Bcl2like1, and Pnrc1 mRNAs were ubiquitously expressed in the brain, except for an increased hippocampal expression (Additional file 5B D). Pcyoxilike, Armc9, 1300010M03Rik, Rad18, and Snapc5 mRNAs were uniformly expressed throughout the brain (Additional file $5 \mathrm{E} \sim \mathrm{I})$.

\section{Identification of genes specifically conserved between vertebrates and red flour beetle but lost from the other sequenced ecdysozoan genomes}

As controls, we used Urbilaterian genes that were uniquely shared between $T$. castaneum and vertebrate (TVS genes) identified in the same method as that used for HVS genes. In contrast to the 30 honey bee HVS genes, red flour beetle TVS genes were only 6 (Table 3 ). We also analyzed the expression patterns of 8 mouse TVS genes in various tissues as described above (Fig. 4). Nearly ubiquitous expression was observed with Gm2a, Naif1, Parp12, Parp11, and Art5 genes. Art2b was predominantly expressed in the lung, spleen, and liver; Rsad2, in the lung, spleen, heart, and kidney; and Crlf3, in the lung and spleen. Thus, none of the mouse TVS genes were expressed in either or both the brain and testis, unlike mouse HVS genes. Moreover, only 1 TVS gene, the poly (ADP-ribose) polymerase family was suggested to have been associated with gene expression in GO terms. Since only 8 mouse TVS genes were identified, it was not possible to statistically compare them with 45 mouse HVS genes. Nevertheless, these results support that honey bees retain more ancient Urbilaterian genes than red flour beetle.

\section{Discussion \\ Evolution of HVS genes}

Searching for HVS genes uniquely shared between vertebrates and honey bee resulted in the identification of 30 honey bee and 55 mouse genes. There are more HVS genes in mice than honey bees since multiple-copy HVS genes are often present in the mouse genomes as against single copy genes in the honey bee genome (Table 2). This finding suggested that Urbilateria had a relatively complex genome and that HVS genes have been lost from various ecdysozoans, which were shown to have more derived genomes than lophotrochozoan and deuterostome [1-7]. The loss and retention of these ancient genes in specific lineages has been implicated in generating metazoan diversity $[3,4]$; however, the causal relationships involved therein have not been extensively studied. There are 2 possibilities explaining the lineage-specific retention and loss of Urbilaterian genes. One possibility is that some genes are retained in specific lineages because during evolution, they may have had vital roles in these lineages but not in others. The other possibility is that many lineages evolved, for example, distant paralogs or gene network interactions, to compensate for the functions of Urbilaterian genes retained in the specific lineages, and the lineages eventually lost these genes. If the latter case is considered, some Urbilaterian genes must have been stochastically retained in specific lineages. We, thus, characterized HVS genes as a model to gain insights into the evolutionary mechanisms resulting in the presence of Urbilaterian genes only in specific lineages.

Table 3: List of red flour beetle and mouse TVS genes

\begin{tabular}{|c|c|c|c|c|}
\hline Tribolium GLEAN & Mouse Accession Number & E-value & \multicolumn{2}{|c|}{ Name/Comments } \\
\hline \multicolumn{5}{|c|}{ Proteins with known domains } \\
\hline GLEAN_08068 & NP_034429 & $6.00 \mathrm{E}-16$ & $\mathrm{Gm} 2 \mathrm{a}$ & GM2 ganglioside activator protein \\
\hline GLEAN_II6I4 & NP_067359 & $8.00 \mathrm{E}-121$ & Rsad2 & radical S-adenosyl methionine domain containing 2 \\
\hline GLEAN_00209 & NP_061246 & $3.00 \mathrm{E}-46$ & Crlf3 & cytokine receptor-like factor 3 \\
\hline \multirow[t]{2}{*}{ GLEAN_10124 } & NP_76648I & $1.00 \mathrm{E}-28$ & Parp 12 & poly (ADP-ribose) polymerase family, member 12 \\
\hline & NP_852067 & $3.00 \mathrm{E}-25$ & Parpll & poly (ADP-ribose) polymerase family, member II \\
\hline \multirow[t]{2}{*}{ GLEAN_04003 } & NP_031517 & $2.00 \mathrm{E}-09$ & Art5 & ADP-ribosyltransferase 5 precursor \\
\hline & NP_064299 & 4.00E-07 & Art2b & ADP-ribosyltransferase $2 b$ \\
\hline
\end{tabular}

Proteins without known domains

GLEAN_10286 NP_919316 I.00E-07 Naifl nuclear apoptosis inducing factor I

The sequences of Tribolium GLEAN models are available in BCM database http://www.hgsc.bcm.tmc.edu/projects/tribolium/. 


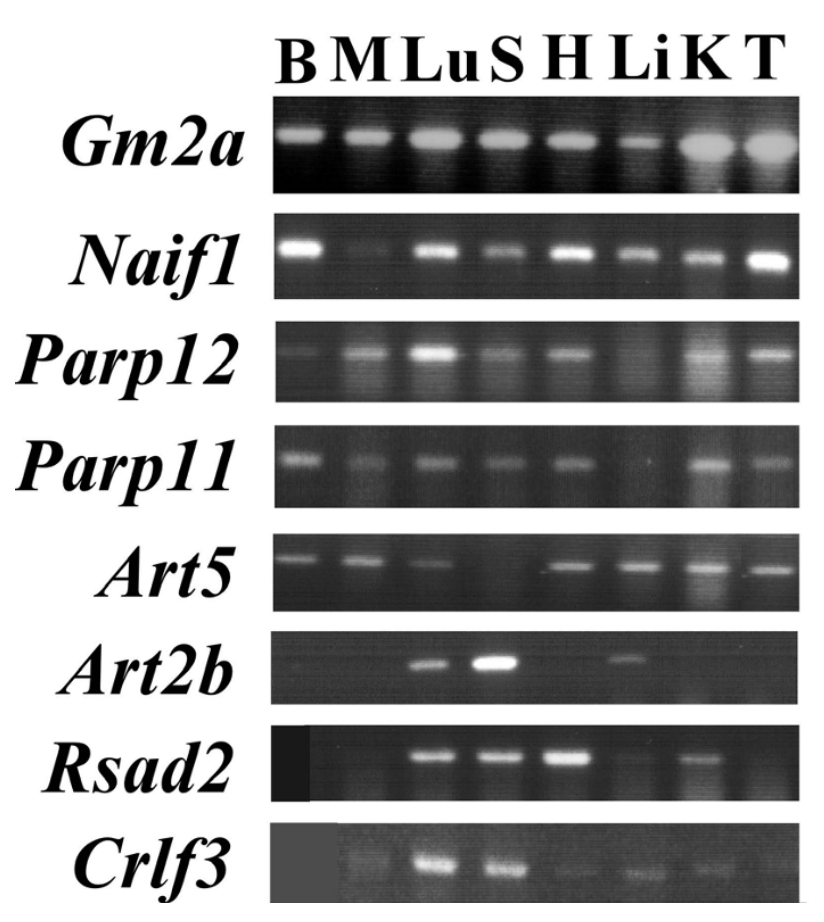

Figure 4

Expression profiles of TVS genes in mouse tissues. TVS mRNA levels in the mouse brain (B), muscle (M), lung $(\mathrm{Lu})$, spleen $(\mathrm{S})$, heart $(\mathrm{H})$, liver $(\mathrm{Li})$, kidney $(\mathrm{K})$, and testis $(\mathrm{T})$ were analyzed by semiquantitative RT-PCR, as shown in Fig. 2. Nearly ubiquitous expression was detected for the genes Gm2a, Naifl, Parp 12, Parp II, and Art5. Art2b mRNA is expressed in the lung, spleen, and liver at high levels. Rsad2 mRNA is abundantly expressed in the lung, spleen, heart, and kidney. High levels of Crlf3 mRNA are expressed in the lung and spleen.

During the course of the identification of honey bee HVS genes, we first identified 40 genes shared between vertebrates and honey bee but not other sequenced insect (fly, mosquitoes, beetle, and moth) genomes. Furthermore, the nematode genome also lost 30 but retained 10 genes, demonstrating that its evolutionary rate was comparable to that of fruit fly and mosquito, as previously reported [29]. Ten genes shared between honey bee and nematode included a Malonyl-CoA decarboxylase responsible for the conversion of Malonyl-CoA to Acetyl-CoA, which is used in fatty acid biosynthesis as well as energy production. These functions should be very critical since this gene is conserved in bacteria and plants. The apparent lack of this enzyme in 5 insect species suggests that these species must have developed an alternative pathway for fatty acid metabolism. The functions of other genes shared between honey bee and nematode have not been reported.

Both sea urchin and ascidian contain a comparable number of HVS genes (Table 2); however, amino acid sub- stitutions are more extensive in ascidian than in sea urchin. When the ascidian genome was searched for HVS genes by TBLASTN analysis using honey bee HVS genes as queries, only 16 genes with significant similarity were recovered. Consistent with previous reports $[30,31]$, this result demonstrates that although ascidian is more closely related to the vertebrate lineage, it has a more derived genome than sea urchin. Honey bees contain a single copy for each HVS gene; however, vertebrates have multiple copies for 15 out of $30(50 \%)$ honey bee HVS genes. This ratio is lower than the average percentage (approximately $70 \%$, [32]) of genes having multiple copies in human and mouse. This may suggest that the loss of gene copy occurred more frequently with HVS genes after whole- or local-genome duplication events in vertebrates [33] (Table 2). The tissue expression patterns of HVS gene pairs are different in many cases (Fig. 2, Additional file 3, and Additional file 4), demonstrating that they either adopted a new function (neofunctionalization) or partitioned old functions (subfunctionalization). Among HVS genes, the copy-number expansions of genes encoding $\mathrm{Bcl} 2$ and TNF receptor superfamilies were detected in vertebrate genomes. Both $\mathrm{Bcl} 2$ and TNF receptor superfamilies control cell death and survival [24,34], a more extensive feature in vertebrates than in honey bee, sea urchin, and ascidian. Interestingly, among the vertebrates examined, the honey bee GB14271 orthologs were only present in mouse and human (mammals). This result suggests that gene loss also occurs in vertebrates, as reported previously $[35,36]$.

To find the paralogs of HVS genes in the sequenced insect genomes, we first identified functional domains in each HVS protein by InterProScan http://www.ebi.ac.uk/Tools/ InterProScan/ and collected these functional domain sequences from Ensembl. We, then, constructed the HMM models by HMMER 2 programs. Insect protein sets of Ensembl, Baylor, and the Aedes genome sequencing consortium were finally searched for the paralogs of HVS proteins by these HMMs with an E-value cutoff level of 1.0. An example indicates that the functions of HVS genes were compensated by the paralogs and/or gene network interactions. Both honey bees and vertebrate express Dnmt1, 2, and 3; however, members of the genus Drosophila express only Dnmt2, while those of Tribolium express Dnmt1 and 2. Nonexpression of Dnmt1 and 3 is consistent with the lack of CpG methylated DNA in Drosophila [37], and Dnmt3 expression is associated with the presence of CpG methylated DNA in honey bee [18]. It is well established that Dnmt3 is de novo DNA methyltransferase, and Dnmt1 is necessary for maintaining DNA methylation in vertebrates [25]. If CpG methylated DNA is present in the Tribolium genome, it can be inferred that Dnmt1, the paralog of Dnmt3, might also carry out de novo DNA methylation. Meanwhile, the epigenetic repression of gene transcription is functional in Drosophila 
through histone modifications, suggesting that Drosophila evolves the epigenetic control system independent of the methylated DNA by mechanisms such as modification of gene network interactions.

\section{Present functions of HVS genes appear to be biased towards expression in the brain and gonads}

Most honey bee HVS genes (83\%, 25 out of 30) were expressed at different levels in the brain, thorax, and abdomen (Fig. 1 and Additional file 2). Among them, $72 \%$ (18 out of 25 ) show a higher level of expression in the brain than in the thorax and abdomen, suggesting that their mRNAs appear to be enriched in the neurons. Most mouse HVS genes $(76 \%, 34$ out of 45$)$ show tissue-specific or selective expression patterns (Fig. 2, Additional file 3 , and Additional file 4). Among them, 32\% (11 out of 34 ) are highly expressed in either or both the brain and testis. Intriguingly, 7 genes are highly expressed in both brain and testis. HVS genes are not essential for the survival of all animals since they are absent in many insect species other than honey bee. These genes are unlikely to have major roles for cell viability and maintenance and, thus, they were easily co-opted or recruited to function in the specific tissues, which in this case were mouse brain and testis. Both tissues contain a significant population of stem cells and, thus, the 7 HVS genes may have specific roles in regulating the proliferation and/or differentiation of these stem cells. Many genes associated with neuronal excitation and transmission are highly expressed in the brain but not in the testis. Meanwhile, genes involved in spermatogenesis are expressed exclusively in the testis and not in the brain. Genes highly expressed in both tissues are, therefore, not very common in mouse. It was reported that the total number of genes predominantly expressed in the human brain and testis is 664 out of the 7070 examined, accounting for only 9.4\% [38]. Thus, the ancient Urbilaterian genes selectively retained between vertebrates and honey bee appear to be biased toward playing major roles in brain and gonad functions in mouse. In agreement with this finding, only 6 red flour beetle TVS genes (genes uniquely shared between red flour beetle and vertebrates) were identified, and no mouse TVS gene exhibited predominant expression either in the brain or testis (Table 3 and Fig. 4). We, therefore, would like to propose that at least some HVS genes might have been selectively maintained in order to support honey bee-specific brain and, possibly, gonad functions. It is very likely that brain functions involved in supporting social behavior and cognitive ability of honey bees and vertebrates evolve independently, without the sharing of any genetic components, on account of their evolutionary distance and the difference in their brain structures; however, selective genes of Urbilateria could be a part of the genetic bases underlying the evolution of advanced brain functions. We found that 13 mouse HVS genes were highly expressed in the neurons of the brain. Among them, 8 genes exhibited brain-region selective expression patterns. Most of them were highly expressed in the cerebellar and in the forebrain area, including the olfactory bulb, cerebral cortex, and hippocampus. These brain regions are responsible for the integration and processing of various sensory information as well as various forms of learning and memory. The roles of many other HVS genes in brain functions in both honey bees and mice remain to be determined.

The number of honey bee HVS genes is only 30 , and this is consistent with the fact that gene loss and acquisition events are relatively rare as compared to amino acid substitution, cis-regulatory mutation, DNA rearrangement, and duplication during evolution. A vast majority of honey bee genes are, indeed, conserved in all solitary ecdysozoan genomes [15], suggesting that advanced honey bee brain functions are primarily driven by increasing complexity in the network of gene interactions. Since 7 out of 20 HVS gene products were predicted, by using GO terms, to be associated with transcription and modification of DNA as well as RNA processing in the nucleus, they could participate in such processes by regulating DNA transcription, splicing, and non-coding RNA synthesis. These HVS genes would provide an important resource for future studies on gene function.

\section{Conclusion}

Large-scale comparison of metazoan genomes has revealed that a significant fraction of genes of Urbilateria is lost in each animal lineage. This event could be one of the underlying mechanisms responsible for metazoan diversity. We have found that HVS genes are biased towards expression in the brains and gonads of honey bees and mice, and 35\% of HVS genes are associated with DNA transcription and RNA processing by GO analysis. These results suggest that HVS genes include genes that are biased towards expression in the brain and gonad. It also demonstrates that at least some of Urbilaterian genes are selectively retained in the specific animal lineage to support the species-specific phenotypes.

\section{Methods \\ Identification of HVS genes}

Protein sets were retrieved from Ensembl for Drosophila, Anopheles, and all vertebrates. Tribolium and Apis proteins were retrieved from Baylor and Aedes proteins from the Aedes genome sequencing consortium. Assignment to orthologous groups was performed as described earlier [39]. In short, we retained the longest ORF per locus and performed all-against-all comparisons using the SmithWaterman algorithm. After grouping paralogous proteins, triangles of reciprocal best hits (involving 3 different species) were joined to build orthologous groups. Starting 
with a stringent cutoff, the joining was repeated with relaxed stringency in each successive step. All proteins in a group were required to have hits overlapping by at least 20 residues to avoid "domain walking" [17].

The candidate genes uniquely shared between honey bees and at least 1 abovementioned vertebrate were further screened by TBLASTN analysis with the genome and gene model (if available) DNA sequences of D. melanogaster, $A$. gambiae, A, aegypti, B. mori, and T. castaneum. Genes demonstrating a similarity to the abovementioned insect DNA sequences with an E value $<\mathrm{E}-03$ were discarded. The resulting 40 genes were then analyzed by TBLASTN with the genome and gene model DNA sequences of $C$. elegans, as described above. Ten genes exhibited significant similarity (E value < 5E-04) to C. elegans genes, and were, therefore, eliminated. These methods resulted in the identification of 30 honey bee genes shared between at least 1 vertebrate and honey bee, but not any of the sequenced ecdysozoan genomes. We used the same strategy to identify genes uniquely shared between red flour beetle and at least 1 vertebrate (TVS genes).

\section{Distribution of HVS genes in deuterostome}

The presence of the above HVS genes in sequenced deuterostome genomes ( $S$. purpuratus, C. intestinalis, T. nigroviridis, X. tropicalis, G. gallus, M. musculus, and H. sapiens) was analyzed by TBLASTN, as described above. Genes exhibiting significant similarity (E value $<$ E-03) to the honey bee HVS genes were scored at first. When homologous genes could not be identified in a particular species, their genomes were further analyzed by TBLASTN using HVS genes of other species (sea urchin, ascidian, and vertebrate) as queries. Once the homologous genes were identified in a particular species, they were used as queries to further screen for multiple-copy genes. If multiple-copy genes were identified, their locations on the contigs, scaffolds, and/or chromosomes were examined to verify them.

\section{Analysis of HVS genes by GO terms}

We predicted HVS gene functions by assigning Gene Ontology (GO) terms (Gene-Ontology database, http:// www.geneontology.org). We searched for GO terms of each HVS gene using the AmiGO search engine. Search was conducted without filtering so that all GO terms were equally considered.

\section{RT-PCR analysis with honey bee and mouse tissues}

Total RNA was isolated from the brain, thorax, and abdomen collected from 20 honey bee workers using Trizol reagent (Invitrogen). Similarly, total RNA was isolated from mouse brain, muscle, lung, spleen, heart, liver, kidney, and testis. Then, $5 \mu \mathrm{g}$ of total RNA was used for reverse transcription reaction with ReverTra Ace reverse transcriptase (TOYOBO). The RT products were then used for PCR with Go Taq DNA polymerase (Promega). The annealing temperature was $5^{\circ} \mathrm{C}$ higher than the $\mathrm{T}_{\mathrm{m}}$ of the primers used, and the extension time was 30 s. PCR was repeated for 25 cycles, wherein the linearity between the band intensity and cycling number was confirmed. However, the cycling number to obtain amplified products was 30 for Snx24, 9230110C19Rik, and Art2b and 35 for GB14271, Tnfrsf4, and Naif1. The RT-PCR products were sequenced to verify their identities. For honey bee HVS genes, the agarose gels were photographed, and the images were processed with Photoshop. The relative intensities of all bands detected for each gene were then measured with NIH image software (Image J). The data are shown in Additional file 1. The primer sequences used for PCR are available on request.

\section{Allen Brain Atlas data processing}

The expression profiles of HVS genes in the mouse brain were classified according to the in situ hybridization and "heat map" (representing signal intensity) data [28]. The expression level in glia was examined by the signal intensity in the white matters of the various brain regions, such as cerebellum.

\section{Authors' contributions}

TM and TY performed RT-PCR and Allen Brain Atlas data processing, SW and EMZ carried out bioinformatic analysis, and TK designed the experiments and wrote the manuscript.

\section{Additional material}

\section{Additional file 1}

The relative values of each band intensity shown in Figure 1 and Additional file 2. The data show the results of quantification of honey bee HVS mRNAs in the brain, thorax, and abdomen.

Click here for file

[http://www.biomedcentral.com/content/supplementary/14712164-10-17-S1.xls]

\section{Additional file 2}

Levels of other HVS mRNAs (not shown in Figure 1) in the honey bee brain, thorax, and abdomen were analyzed by semiquantitative $R T$ PCR. GB13403, GB18344, GB18937, and GB16350 mRNAs are ubiquitously expressed (Ubiquitous). GB14717, GB16908, GB11010, GB14271, GB18120, GB19146, GB10273, GB14468, GB18761, GB15533, GB15999, GB17835, GB19733, GB17260, GB18050, GB10755, GB18346 mRNAs are highly expressed in the brain (Brain). Click here for file

[http://www.biomedcentral.com/content/supplementary/14712164-10-17-S2.tiff] 


\section{Additional file 3}

Levels of other HVS mRNAs (not shown in Figure 2) in the mouse brain (B), muscle (M), lung (Lu), spleen (S), heart $(H)$, liver (Li), kidney $(K)$, and testis $(T)$ were analyzed by semiquantitative RT-PCR. Dnmt3a, Mtfr1, Armc1, Pnrc2, 1300010M03Rik, Fbxlike3, Gemin7, Siva1, LOC434405, and Fbxo22 mRNAs are ubiquitously present (Ubiquitous). Pnrc1 and Rad18 mRNAs are predominantly expressed in the brain (Brain) and testis (Testis), respectively. Dnmt3b, Cdca7, LOC217738, 1700012P22Rik, 2610016C23Rik, and Armc9 $m R N A s$ are present in the brain and testis in high levels (Brain and Testis).

Click here for file

[http://www.biomedcentral.com/content/supplementary/14712164-10-17-S3.tiff]

\section{Additional file 4}

Levels of other HVS mRNAs (not shown in Figure 2 and Additional file 3) in the mouse brain (B), muscle (M), lung (Lu), spleen (S), heart $(H)$, liver $(L i)$, kidney $(K)$, and testis $(T)$ were analyzed by semiquantitative RT-PCR. Cdca7like and 2010001M09Rik mRNAs are primarily expressed in the brain, lung, spleen, kidney, and testis. Snapc5 and Bcllike 1 are expressed in all tissues examined, except in the muscle. All other genes (16 out of 45), Bcl2, Ccdc111, Snx22, Rtkn, Tuba, Pcyox1like, Hop, Bin3, Tnfrsf4, Tnfrsf14, Tmem45b, Tmem45a, Fbxlike21, 1810015C04Rik, 9230110C19Rik, and 6430571L13Rik show different tissue-selective expression patterns.

Click here for file

[http://www.biomedcentral.com/content/supplementary/14712164-10-17-S4.tiff]

\section{Additional file 5}

Spatial expression patterns of Fbxo22, Pcyox1, Bcl2like1, Pnrc1, Pcyox1like, Armc9, 1300010M03Rik, Rad18, and Snapc5 mRNAs in the adult mouse brain. Fbxo22 $m R N A$ is expressed in both neurons and glias throughout the brain (A). Pcyox1 (B), Bcl2like1 (C), Pnrc1 (D) mRNAs are ubiquitously expressed in the brain; however, they are abundantly expressed in the hippocampus (HIP). Pcyox1like (E), Armc9 (F), 1300010M03Rik (G), Rad18 (H), and Snapc5 (I) $m R N A s$ are ubiquitously present throughout the brain.

Click here for file

[http://www.biomedcentral.com/content/supplementary/14712164-10-17-S5.tiff]

\section{Acknowledgements}

This study was supported by Grant-in-Aid for Scientific Research from the Japan Society for the Promotion of Science to TK, and Swiss National Science Foundation grant SNF 3100A0-I I2588/I to EMZ.

\section{References}

I. Kortschak RD, Samuel G, Saint R, Miller DJ: EST analysis of the Cnidarian Acropora millepora reveals extensive gene loss and rapid sequence divergence in the model invertebrates. Current Biol 2003, 13:2190-2195.

2. Kusserow A, Pang K, Sturm C, Hrouda M, Lentfer J, Schmidt HA, Technau U, von Haeseler A, Hobmayer B, Martindale MQ, Holstein TW: Unexpected complexity of the Wnt gene family in a sea anemone. Nature 2005, 433:156-160.

3. Technau U, Rudd S, Maxwell P, Gordon PMK, Saina M, Grasso LC Hayward DC, Sensen CW, Saint R, Holstein TW, Ball EE, Miller DJ: Maintenance of ancestral complexity and non-metazoan genes in two basal cnidarians. Trends Genet 2005, 21:633-639.
4. Miller DJ, Ball EE, Technau U: Cnidarians and ancestral genetic complexity in the animal kingdom. Trends Genet 2005, 21:536-539.

5. Moroz LL, Edwards JR, Puthanveettil SV, Kohn AB, Ha T, Heyland A Knudsen B, Sahni A, Yu F, Liu L, Jezzini S, Lovell P, lannucculli W, Chen M, Nguyen T, Sheng H, Shaw R, Kalachikov S, Panchin YV, Farmerie W, Russo J], Ju J, Kandel ER: Neuronal transcriptome of Aplysia: Neuronal compartments and circuitry. Cell 2006, I 27:1453-1467.

6. Raible F, Tessmar-Raible K, Osoegawa K, Wincker P, Jubin C, Balavoine G, Ferrier D, Benes V, de Jong P, Weissenbach J, Bork P, Arendt $D$ : Vertebrate-type intron-rich genes in the marine annelid Platynereis dumerilii. Science 2005, 3 10:1325-1326.

7. De Robertis EM: Evo-Devo: Variations on ancestral themes. Cell 2008, 132: 185-195.

8. Fahrbach SE, Robinson GE: Behavioral development in the honey bee: Toward the study of learning under natural conditions. Learn \& Mem 1995, 2:199-224.

9. Menzel R, Muller U: Learning and memory in honeybees: From behavior to neural substrates. Annu Rev Neurosci 1996, 19:379-404.

10. Menzel R, Giurfa M: Cognitive architecture of a mini-brain: the honeybee. Trends Cogn Sci 200I, 5:62-7I.

II. Drosophila 12 Genomes Consortium: Evolution of genes and genomes on the Drosophila phylogeny. Nature 2007, 450:203-218.

12. Holt RA, Subramanian GM, Halpern A, Sutton GG, Charlab R, Nusskern DR, Wincker P, Clark AG, Ribeiro JM, Wides R, Salzberg SL, Loftus B, Yandell M, Majoros WH, Rusch DB, Lai Z, Kraft CL, Abril JF, Anthouard V, Arensburger P, Atkinson PW, Baden H, de Berardinis V, Baldwin D, Benes V, Biedler J, Blass C, Bolanos R, Boscus D, Barnstead M, Cai S, Center A, Chaturverdi K, Christophides GK, Chrystal MA, Clamp M, Cravchik A, Curwen V, Dana A, Delcher A, Dew I, Evans CA, Flanigan M, Grundschober-Freimoser A, Friedli L, Gu Z, Guan P, Guigo R, Hillenmeyer ME, Hladun SL, Hogan JR, Hong YS, Hoover J, Jaillon O, Ke Z, Kodira C, Kokoza E, Koutsos A, Letunic I, Levitsky A, Liang Y, Lin J], Lobo NF, Lopez JR, Malek JA, McIntosh TC, Meister S, Miller J, Mobarry C, Mongin E, Murphy SD, O'Brochta DA, Pfannkoch C, Qi R, Regier MA, Remington K, Shao H, Sharakhova MV, Sitter CD, Shetty J, Smith TJ, Strong R, Sun J, Thomasova D, Ton LQ, Topalis P, Tu Z, Unger MF, Walenz B, Wang A, Wang J, Wang M, Wang X, Woodford KJ, Wortman JR, Wu M, Yao A, Zdobnov EM, Zhang H, Zhao Q, Zhao S, Zhu SC, Zhimulev I, Coluzzi M, della Torre A, Roth CW, Louis C, Kalush F, Mural RJ, Myers EW, Adams MD, Smith HO, Broder S, Gardner MJ, Fraser CM, Birney E, Bork P, Brey PT, Venter JC, Weissenbach J, Kafatos FC, Collins FH, Hoffman SL: The genome sequence of the malaria mosquito Anopheles gambiae. Science 2002, 298:129-149.

13. Nene V, Wortman JR, Lawson D, Haas B, Kodira C, Tu ZJ, Loftus B, Xi Z, Megy K, Grabherr M, Ren Q, Zdobnov EM, Lobo NF, Campbell KS, Brown SE, Bonaldo MF, Zhu J, Sinkins SP, Hogenkamp DG, Amedeo P, Arensburger P, Atkinson PW, Bidwell S, Biedler J, Birney E, Bruggner RV, Costas J, Coy MR, Crabtree J, Crawford M, Debruyn B, Decaprio D, Eiglmeier K, Eisenstadt E, El-Dorry H, Gelbart WM, Gomes SL, Hammond M, Hannick LI, Hogan JR, Holmes MH, Jaffe D, Johnston JS, Kennedy RC, Koo H, Kravitz S, Kriventseva EV, Kulp D, Labutti K, Lee E, Li S, Lovin DD, Mao C, Mauceli E, Menck CF, Miller JR, Montgomery P, Mori A, Nascimento AL, Naveira HF, Nusbaum C, O'leary S, Orvis J, Pertea M, Quesneville H, Reidenbach KR, Rogers YH, Roth CW, Schneider JR, Schatz M, Shumway M, Stanke M, Stinson EO, Tubio JM, Vanzee JP, Verjovski-Almeida S, Werner D, White O, Wyder S, Zeng Q, Zhao Q, Zhao Y, Hill CA, Raikhel AS, Soares MB, Knudson DL, Lee NH, Galagan J, Salzberg SL, Paulsen IT, Dimopoulos G, Collins FH, Birren B, Fraser-Liggett CM, Severson DW: Genome sequence of Aedes aegypti, a major arbovirus vector. Science 2007, 316:1718-1723.

14. Biology analysis group: A draft sequence for the genome of the domesticated silkworm (Bombyx mori). Science 2004, 306:1937-1940.

15. The honeybee genome sequencing consortium: Insights into social insects from the genome of honeybee Apis mellifera. Nature 2006, 443:931-949.

16. Tribolium genome sequencing consortium: The genome of the model beetle and pest Tribolium castaneum. Nature 2008, 452:949-955. 
17. Wyder S, Kriventseva E, Schroder R, Kadowaki T, Zdobnov EM: Quantification of ortholog losses in insects and vertebrates. Genome Biology 2007, 8:R242.

18. Wang $\mathrm{Y}$, Jorda $\mathrm{M}$, Jones $\mathrm{PL}$, Maleszka R, Ling $\mathrm{X}$, Robertson HM, Mizzen CA, Peinado MA, Robinson GE: Functional CpG methylation system in a social insect. Science 2006, 3 I 4:645-647.

19. Muhlfriedel S, Kirsch F, Gruss P, Stoykova A, Chowdhury K: A roof plate-dependent enhancer controls the expression of Homeodomain only protein in the developing cerebral cortex. Dev Biol 2005, 283:522-534

20. Chen F, Kook H, Milewski R, Gitler AD, Lu MM, Li J, Nazarian R, Schnepp R, Jen K, Biben C, Runke G, Mackay JP, Novotny J, Schwartz RJ, Harvey RP, Mullins MC, Epstein JA: Hop is an unusual homeobox gene that modulates cardiac development. Cell 2002 I I 0:713-723.

2I. Shin CH, Liu Z-P, Passier R, Zhang C-L, Wang D-Z, Harris TM, Yamagishi H, Richardson JA, Childs G, Olson EN: Modulation of cardiac growth and development by HOP, an unusua homeodomain protein. Cell 2002, I I 0:725-735.

22. Salazar MA, Kwiatkowski AV, Pellegrini L, Cestra G, Butler MH, Rossman KL, Serna DM, Sondek J, Gertler FB, De Camilli P: Tuba, a novel protein containing Bin/Amphiphysin/Rvs and Dbl homology domains, links dynamin to regulation of the actin cytoskeleton. J Biol Chem 2003, 278:4903I-49043

23. Beigneux A, Withycombe SK, Digits JA, Tschantz WR, Weinbaum CA, Griffey SM, Bergo M, Casey PJ, Young SG: Prenylcysteine lyase deficiency in mice results in the accumulation of farnesylcysteine and geranylgeranylcysteine in brain and liver. J Biol Chem 2002, 277:38358-38363.

24. Korsmeyer SJ: Bcl-2 initiates a new category of oncogenes: regulator of cell death. Blood 1992, 80:879-886.

25. Okano M, Bell DW, Haber DA, En Li: DNA methyltransferases Dnmt3a and Dnmt3b are essential for de novo methylation and mammalian development. Cell 1999, 99:247-257.

26. Tateishi S, Niwa H, Miyazaki J, Fujimoto S, Inoue H, Yamaizumi M Enhanced genomic instability and defective postreplication repair in RAD I 8 knockout mouse embryonic stem cells. Mol Cell Biol 2003, 23:474-48I.

27. Mi H, Vandergriff J, Campbell M, Narechania A, Majoros W, Lewis S, Thomas PD, Ashburner M: Assessment of genome-wide protein function classification for Drosophila melanogaster. Genome Res 2003, I3:21 I8-2128.

28. Lein ES, Hawrylycz MJ, Ao N, Ayres M, Bensinger A, Bernard A, Boe AF, Boguski MS, Brockway KS, Byrnes EJ, Chen L, Chen L, Chen TM, Chin MC, Chong J, Crook BE, Czaplinska A, Dang CN, Datta S, Dee NR, Desaki AL, Desta T, Diep E, Dolbeare TA, Donelan MJ, Dong HW, Dougherty JG, Duncan BJ, Ebbert AJ, Eichele G, Estin LK, Faber C, Facer BA, Fields R, Fischer SR, Fliss TP, Frensley C, Gates SN, Glattfelder KJ, Halverson KR, Hart MR, Hohmann JG, Howell MP, Jeung DP, Johnson RA, Karr PT, Kawal R, Kidney JM, Knapik RH, Kuan CL, Lake JH, Laramee AR, Larsen KD, Lau C, Lemon TA, Liang AJ, Liu Y, Luong LT, Michaels J, Morgan JJ, Morgan RJ, Mortrud MT, Mosqueda NF, Ng LL, Ng R, Orta G], Overly CC, Pak TH, Parry SE, Pathak SD, Pearson OC, Puchalski RB, Riley ZL, Rockett HR, Rowland SA, Royall J), Ruiz MJ, Sarno NR, Schaffnit K, Shapovalova NV, Sivisay T, Slaughterbeck CR, Smith SC, Smith KA, Smith BI, Sodt AJ, Stewart NN, Stumpf KR, Sunkin SM, Sutram M, Tam A, Teemer CD, Thaller C, Thompson CL, Varnam LR, Visel A, Whitlock RM, Wohnoutka PE, Wolkey CK, Wong VY, Wood M, Yaylaoglu MB, Young RC, Youngstrom BL, Yuan XF, Zhang B, Zwingman TA, Jones AR: Genomewide atlas of gene expression in the adult mouse brain. Nature 2007, 445: 168-176.

29. Mushegian AR, Garey JR, Martin J, Liu LX: Large-scale taxonomic profiling of eukaryotic model organisms: A comparison of orthologous proteins encoded by the human, fly, nematode and yeast genomes. Genome Res 1998, 8:590-598.

30. Dehal P, Satou Y, Campbell RK, Chapman J, Degnan B, De Tomaso A Davidson B, Di Gregorio A, Gelpke M, Goodstein DM, Harafuji N, Hastings KE, Ho I, Hotta K, Huang W, Kawashima T, Lemaire P, Martinez D, Meinertzhagen IA, Necula S, Nonaka M, Putnam N, Rash S, Saiga H, Satake M, Terry A, Yamada L, Wang HG, Awazu S, Azumi K, Boore J, Branno M, Chin-Bow S, DeSantis R, Doyle S, Francino P, Keys DN, Haga S, Hayashi H, Hino K, Imai KS, Inaba K, Kano S, Kobayashi K, Kobayashi M, Lee BI, Makabe KW, Manohar C, Matassi G, Medina M, Mochizuki Y, Mount S, Morishita T, Miura S, Nakayama A Nishizaka S, Nomoto H, Ohta F, Oishi K, Rigoutsos I, Sano M, Sasaki
A, Sasakura Y, Shoguchi E, Shin-i T, Spagnuolo A, Stainier D, Suzuki MM, Tassy O, Takatori N, Tokuoka M, Yagi K, Yoshizaki F, Wada S, Zhang C, Hyatt PD, Larimer F, Detter C, Doggett N, Glavina T, Hawkins T, Richardson P, Lucas S, Kohara Y, Levine M, Satoh N, Rokhsar DS: The draft genome of Ciona intestinalis: Insights into Chordate and vertebrate origin. Science 2002 298:2157-2167.

31. Hughes AL, Friedman R: Loss of ancestral genes in the genomic evoluition of Ciona intestinalis. Evol \& Dev 2005, 7:196-200.

32. Zhang $\mathrm{L}$, $\mathrm{Li} \mathrm{W}-\mathrm{H}$ : Mammalian housekeeping genes evolve more slowly than tissue-specific genes. Mol Biol Evol 2004 21:236-239.

33. Dehal $\mathrm{P}$, Boore JL: Two rounds of whole genome duplication in the ancestral vertebrate. PLoS Biol 2005, 3:e3 I4.

34. Ware CF: The TNF superfamily. Cytokine Growth Factor Rev 2003 I4:181-184

35. Blomme T, Vandepoele K, De Bodt S, Simillion C, Maere S, Peer Y $V$ an de: The gain and loss of genes during $\mathbf{6 0 0}$ million years of vertebrate evolution. Genome Biol 2006, 7:R43

36. Danchin EG], Gouret P, Pontarotti P: Eleven ancestral gene families lost in mammals and vertebrates while otherwise universally conserved in animals. BMC Evol Biol 2006, 6:5.

37. Kunert N, Marhold J, Stanke J, Stach D, Lyko F: A Dnmt2-like protein mediates DNA methylation in Drosophila. Development 2003, I30:5083-5090.

38. Hsiao LL, Dangond F, Yoshida T, Hong R, Jensen RV, Misra J, Dillon W, Lee KF, Clark KE, Haverty P, Weng Z, Mutter GL, Frosch MP, Macdonald ME, Milford EL, Crum CP, Bueno R, Pratt RE, Mahadevappa M, Warrington JA, Stephanopoulos G, Stephanopoulos $G$, Gullans SR: A compendium of gene expression in normal human tissues. Physiol Genomics 2001, 7:97-104.

39. Zdobnov EM, von Mering C, Letunic I, Torrents D, Suyama M, Copley RR, Christophides GK, Thomasova D, Holt RA, Subramanian GM, Mueller HM, Dimopoulos G, Law JH, Wells MA, Birney E, Charlab R, Halpern AL, Kokoza E, Kraft CL, Lai Z, Lewis S, Louis C, Barillas-Mury C, Nusskern D, Rubin GM, Salzberg SL, Sutton GG, Topalis P, Wides R, Wincker P, Yandell M, Collins FH, Ribeiro J, Gelbart WM, Kafatos FC, Bork P: Comparative genome and proteome analysis of Anopheles gambiae and Drosophila melanogaster. Science 2002 , 298:149-159.

Publish with Biomed Central and every scientist can read your work free of charge

"BioMed Central will be the most significant development for disseminating the results of biomedical research in our lifetime. "

Sir Paul Nurse, Cancer Research UK

Your research papers will be:

- available free of charge to the entire biomedical community

- peer reviewed and published immediately upon acceptance

- cited in PubMed and archived on PubMed Central

- yours - you keep the copyright
BioMedcentral 